\title{
Identification of Factors That Cause Genotype by Environment Interaction Between Herds of Holstein Cattle in Seventeen Countries
}

\author{
N. R. Zwald*, K. A. Weigel*, W. F. Fikse†, and R. Rekaya \\ *Department of Dairy Science \\ University of Wisconsin, Madison 53706 \\ †Interbull Centre, \\ Department of Animal Breeding and Genetics, \\ Swedish University of Agricultural Sciences, \\ S-570 07 Uppsala, Sweden
}

\begin{abstract}
Currently, the International Bull Evaluation Service calculates international dairy sire evaluations using the multiple-trait across country evaluation procedure. This method depends implicitly on political boundaries between countries, because the input data are national evaluations from each participating country. Therefore, different countries are treated as different production environments. The goal of this study was to identify factors that describe the production system on each farm. Such factors could be used to group herds across countries for borderless genetic evaluations. First lactation milk records of Holstein cows calving between January 1, 1990 and December 31, 1997 in Australia, Austria, Belgium, Canada, Czech Republic, Estonia, Finland, Germany, Hungary, Ireland, Israel, Italy, The Netherlands, New Zealand, South Africa, Switzerland, and the USA were used in this study. Thirteen genetic, management, and climatic variables were considered as potential indicators of production environments: peak milk yield, persistency, herd size, age at first calving, seasonality of calving, standard deviation of milk yield, culling rate, days to peak yield, fat to protein ratio, sire PTA milk, percentage of North American Holstein genes, maximum monthly temperature, and annual rainfall. Herds were grouped into quintiles based on herd averages for each of these variables. Genetic correlations for lactation milk yield between quintiles were significantly less than one for maximum monthly temperature, sire PTA milk, percent North American Holstein genes, herd size, and peak milk yield. The variables can be used to group herds into similar production environments, regardless of country borders, for the purpose of accounting for genotype by environment interaction in international dairy sire evaluation.
\end{abstract}

Received June 18, 2002.

Accepted August 30, 2002.

Corresponding author: Nate Zwald; e-mail: nrzwald@calshp.cals. wisc.edu.
(Key words: international evaluation, genotype by environment interaction, production systems)

Abbreviation key: Interbull = International Bull Evaluation Service, MACE = multiple-trait across country evaluation.

\section{INTRODUCTION}

Historically, genetic selection has been practiced within countries. Due to the globalization of the dairy cattle genetics industry (Banos and Smith, 1991), acrosscountry selection has become more important. Global selection can increase rates of genetic response by up to 17\% compared to within-country selection (Lohuis and Dekkers, 1998). With the development of the International Bull Evaluation Service (Interbull) (Banos and Sigurdson, 1996), genetic information from foreign bulls has become easily comprehensible, and use of international sires has become typical for many producers (Weigel and Zwald, 2002). Currently, Interbull calculates international dairy sire evaluations using data from sires used in one or more member countries (http://www.interbull.org). This practice has become possible through global trade of semen and embryos, which have made the international dairy population more closely connected by increasing the average relationship between animals in different countries. The multiple-trait across country evaluation (MACE) procedure (Schaeffer, 1994) is used, and the international evaluation of each bull on the scale of each member country is a function of the number of progeny in each country and the genetic correlations between countries. Genetic correlations between countries are estimated from common bulls and three-quarter sibs that have progeny in multiple countries. These correlations are less than unity because of genotype by environment interaction, differences in trait definitions, and differences in data collection and analysis procedures. Current practices ignore genotype by environment interactions within large countries; all herds within a country like the US are assumed to have the same production 
system (Weigel and Rekaya, 2000). However, large herds in the hot, dry climate of the Southwest are under much different climate and management conditions than small herds in a cool, wet climate of the Midwest or Northeast. Correspondingly, small countries that share a common border may have many herds within very close proximity and with similar management practices, but these countries are treated as different production environments. Therefore, effects of certain important environmental factors and their interactions with genetic effects could be accounted for more precisely if one could develop genetic evaluations for each similar management scheme rather than for each country (Cromie, et al., 1998).

The objective of this study was to identify variables that are useful indicators of genotype by environment interaction among herds. Ultimately, this information will be used to group herds into several generally defined production environments in a borderless evaluation system that features predicted sire breeding values for each of these production systems.

\section{MATERIALS AND METHODS}

\section{Data}

Test-day milk weights were obtained from first parity cows in Australia, Austria, Belgium, Canada, Czech Republic, Estonia, Finland, Germany, Hungary, Ireland, Israel, Italy, The Netherlands, New Zealand, South Africa, Switzerland, and the USA. Holstein-sired cows that calved between January 1, 1990 and December 31, 1997 were included. Cows were excluded if their first reported test date occurred $>90 \mathrm{~d}$ postpartum, or if only one test date occurred during the lactation. A total of 131,907,373 test day records from $16,403,413$ cows and 233,673 herds were used. Test-day milk weights were combined into lactation yields using Wood's function (Rekaya et al., 2000). Lactations were extended to $270 \mathrm{~d}$ (New Zealand), $290 \mathrm{~d}$ (South Africa, Australia, and Ireland), or $305 \mathrm{~d}$ (all other countries) using reference curves developed from cows with completed lactations in each region by production level class (Weigel and Rekaya, 2000). Climate information was obtained for each region using a 10-yr average from www.worldclimate.com. Large countries such as the United States, Canada and Australia, which divide herds into regions for DHI recording, had one reading for each state or providence. Other, smaller countries such as Belgium and The Netherlands had a single temperature and rainfall reading for the whole country.

\section{Grouping Herds}

Herd averages were calculated for each of the thirteen descriptive variables and herds were subsequently di- vided into groups. Independent random samples of herds comprising of roughly $2,500,000$ cows were taken for each of the thirteen variables, and these were divided into quintile groups containing approximately 500,000 cows each. To ensure representation of multiple countries per quintile, a minimum of four countries was required per quintile group. The lowest 20 percent of herds for each variable were in quintile one; herds in the second 20 percent were in quintile two, etc., with the highest herds comprising quintile five (Table 1). Herds with fewer than five observations were omitted from country averages for day of calving, standard deviation of milk yield, and percent of animals with completed lactations. A heterogeneous variance adjustment was applied using the method of Wiggans and VanRaden (1991).

Due to computational constraints, a sire model was used. The multiple-trait model treated milk production as a different trait in each quintile group. A random herd-year-season effect was used because the large proportion of very small herds would have led to inaccurate estimates had this effect been fixed. Fixed herd and fixed year effects were included to account for non-random use of sires over time and across herds. The model was as follows:

$$
\begin{gathered}
\mathrm{y}_{\mathrm{ijklmnop}}=\text { hys }_{\mathrm{i}}+\operatorname{Herd}_{\mathrm{j}}+\operatorname{Year}_{\mathrm{k}}+\text { Breed }_{\mathrm{l}}+\text { Age }_{\mathrm{m}}+\mathrm{MF}_{\mathrm{n}} \\
+\operatorname{sire}_{\mathrm{o}}+\mathrm{e}_{\mathrm{ijklmnop}}
\end{gathered}
$$

where

$$
\begin{aligned}
\mathrm{y}_{\mathrm{ijklmnop}}= & \text { Lactation milk yield; } \\
\text { hys }_{\mathrm{i}}= & \text { Random herd-year-season effect; } \\
\text { Herd }_{\mathrm{j}}= & \text { Fixed herd effect; } \\
\text { Year }_{\mathrm{k}}= & \text { Fixed year effect }(8 \text { levels, 1990-1997); } \\
\text { Breed }_{\mathrm{l}}= & \text { Fixed breed composition effect }(7 \text { levels, } \\
& 100 \% \text { Holstein, Holstein } \times \text { Red, Holstein } \times \\
& \text { Simmental, Holstein } \times \text { Jersey, Holstein } \times \\
& \text { Friesian Holstein (Dutch), Holstein } \times 2 \\
& \text { other breeds, and all others); } \\
\text { Age }_{\mathrm{m}}= & \text { Fixed age at calving effect }(12 \text { levels }) 20- \\
& 22 \mathrm{mo}, 23 \mathrm{mo}, 24 \mathrm{mo}, 25 \mathrm{mo}, 26 \mathrm{mo}, 27 \mathrm{mo}, \\
& 28 \mathrm{mo}, 29 \mathrm{mo}, 30 \mathrm{mo}, 31 \mathrm{mo}, 32 \mathrm{mo}, 33-36 \mathrm{mo} ; \\
\mathrm{MF}_{\mathrm{n}}= & \text { Fixed milking frequency effect }(2 \text { levels, } \\
& 2 \mathrm{X}-3 \mathrm{X}) ; \\
\text { sire }_{\mathrm{o}}= & \text { Random sire effect (with male relation- } \\
& \text { ships); and } \\
\mathrm{e}_{\mathrm{jklmnop}}= & \text { Random residual }
\end{aligned}
$$

Bayesian implementation via Gibbs sampling was used to estimate the covariance matrix corresponding to each variable so that heritability within each quintile and genetic correlations between quintiles could be examined. Uniform, bounded priors were used for all parameters except a normal prior was used for the sire 
Table 1. Mean level of each variable for each of the five quintiles.

\begin{tabular}{lccccc}
\hline Variable & Quintile 1 & Quintile 2 & Quintile 3 & Quintile 4 & Quintile 5 \\
\hline Peak yield (kg) & 18.4 & 23.1 & 25.6 & 28 & 31.8 \\
Persistency & 0.618 & 0.732 & 0.777 & 0.817 & 0.877 \\
Avg. age at calving & 24.3 & 26.1 & 27.6 & 29.2 & 31.7 \\
Fat:protein ratio & 1.12 & 1.19 & 1.26 & 1.31 & 1.36 \\
Inverse of the culling ratio & 0.667 & 0.746 & 0.800 & 0.857 & 0.941 \\
Days to peak yield & 47.8 & 58.4 & 67.2 & 78.6 & 99.6 \\
Avg. calving day & 182 & $182 \pm 15$ & $182 \pm 31$ & $182 \pm 46$ & $182 \pm 61$ \\
\% N.A. Holstein & 23.0 & 61.4 & 78.6 & 87.9 & 97.2 \\
SD milk yield & 568 & 778 & 926 & 1066 & 1278 \\
Average PTAM of sires & -540 & -179 & 133 & 505 & 917 \\
1st lactation animals per yr & 2.5 & 5.25 & 8.875 & 14.3 & 30 \\
Max. temperature $\left({ }^{\circ} \mathrm{C}\right)$ & 17.1 & 21.7 & 23 & 25.5 & 28.5 \\
Avg. yearly rainfall $(\mathrm{cm})$ & 21.9 & 28.4 & 30.1 & 32.7 & 45 \\
\hline
\end{tabular}

effect. A single chain of 70,000 iterations was run, with initial 10,000 iterations used for a burn-in based on trace plot. This resulted in 13 separate $5 \times 5$ variance-covariance matrices that represented each quintile of herds for each variable.

After the multiple-trait analysis, covariance functions were fit to the resulting covariance matrices using second order (Pool and Meuwissen, 2000) Legendre Polynomials (Kirkpatrick et al., 1990). Herd averages were standardized to be continuous between -1 and 1 , such that the mean of herds in the lowest quintile was equal to -1 , and the mean of the herds in the highest quintile was equal to 1 . This allowed application of a continuous function, and specific sire breeding values could be predicted for each individual herd. These functions were shown graphically, with each figure (1-13) representing genetic correlations between high, medium, and low herds with all other herds for each variable. A detailed description of the herd management variables and a summary of country averages for each of these thirteen variables was published by Zwald et al. (2001).

\section{RESULTS AND DISCUSSION}

In each figure, the $5 \times 5$ heritability-correlation matrix that was produced via Gibbs sampling is shown. A second order covariance function was fit to this data to smooth the correlation curve and to estimate correlations between herds at levels between exact quintile levels. Within quintile heritability estimates are shown on the diagonal and genetic correlations between the quintile groups for each variable are on the off diagonal in Figures

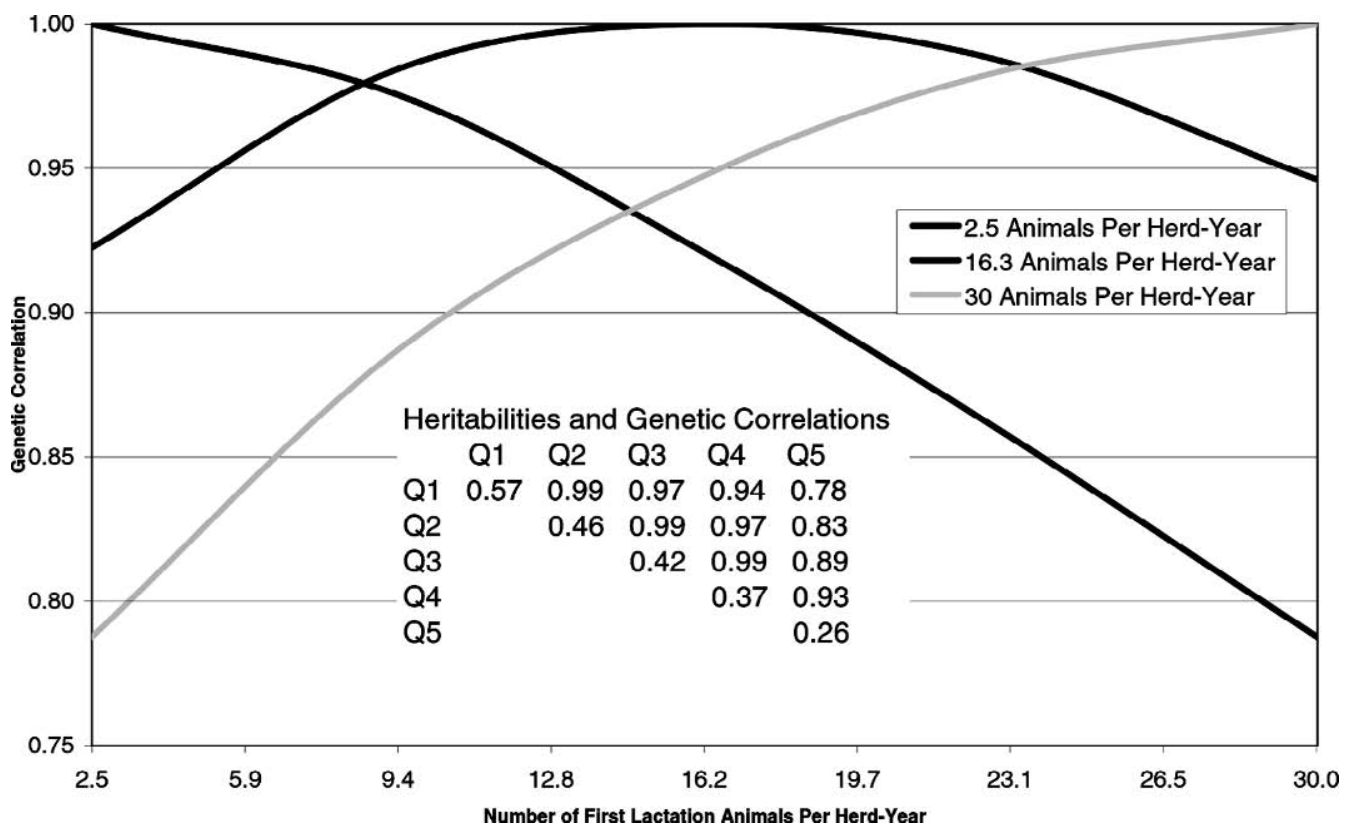

Figure 1. Heritabilities and genetic correlations for herds of varying sizes. 


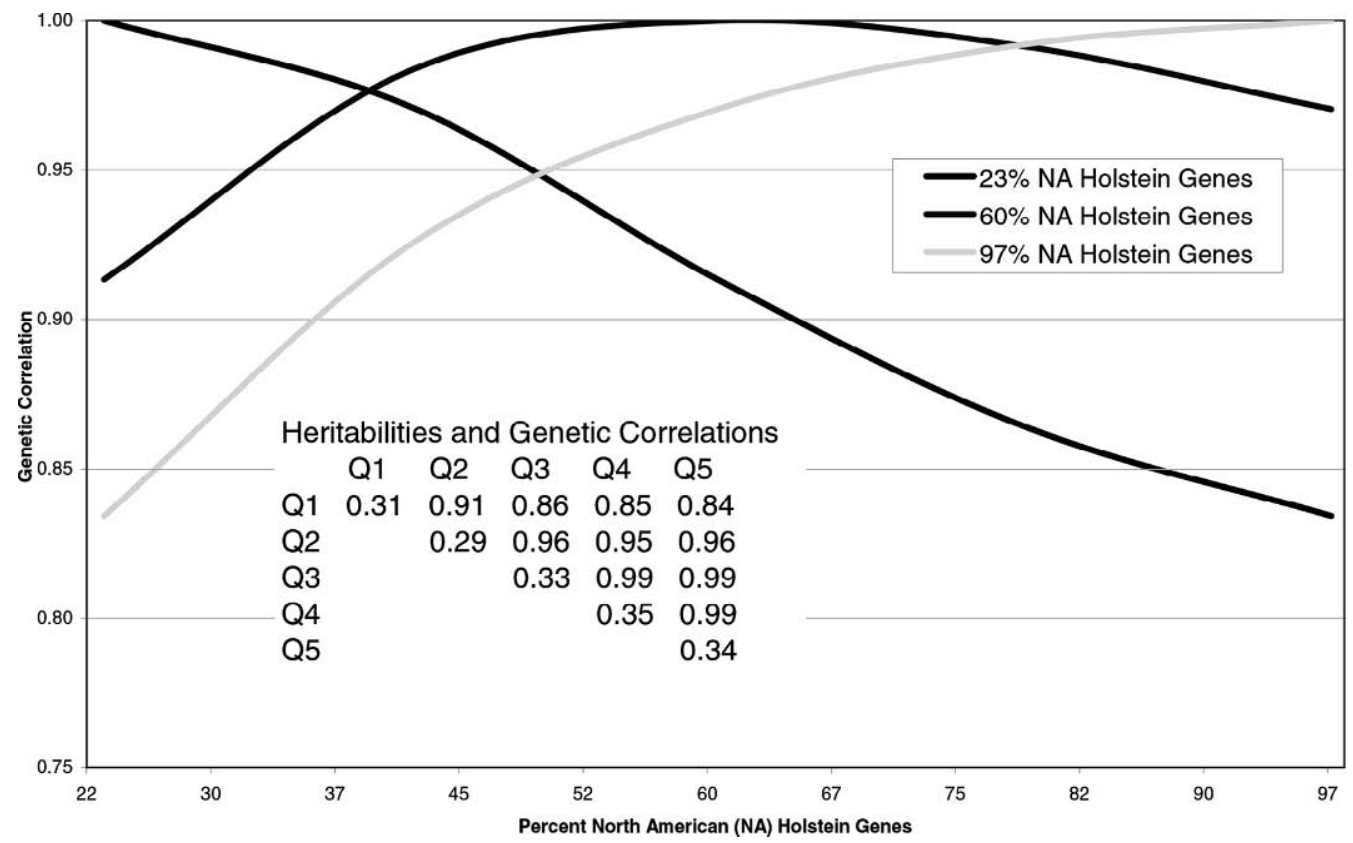

Figure 2. Heritabilities and genetic correlations for herds with varying percentages of North American Holstein genes.

1-13. Genetic correlations are presented as the predicted correlation curves from the second-order polynomial regression. One limitation of this study is that only sire relationships are used. This could affect results because certain quintiles may be made up of more crossbred animals than other quintiles.
Herd size, peak milk yield, temperature, and percent North American Holstein genes had the lowest genetic correlations between quintiles, which signified an importance in defining unique production environments. Herd size (Figure 1) was characterized by large differences in heritabilities and genetic correlations between quintiles.

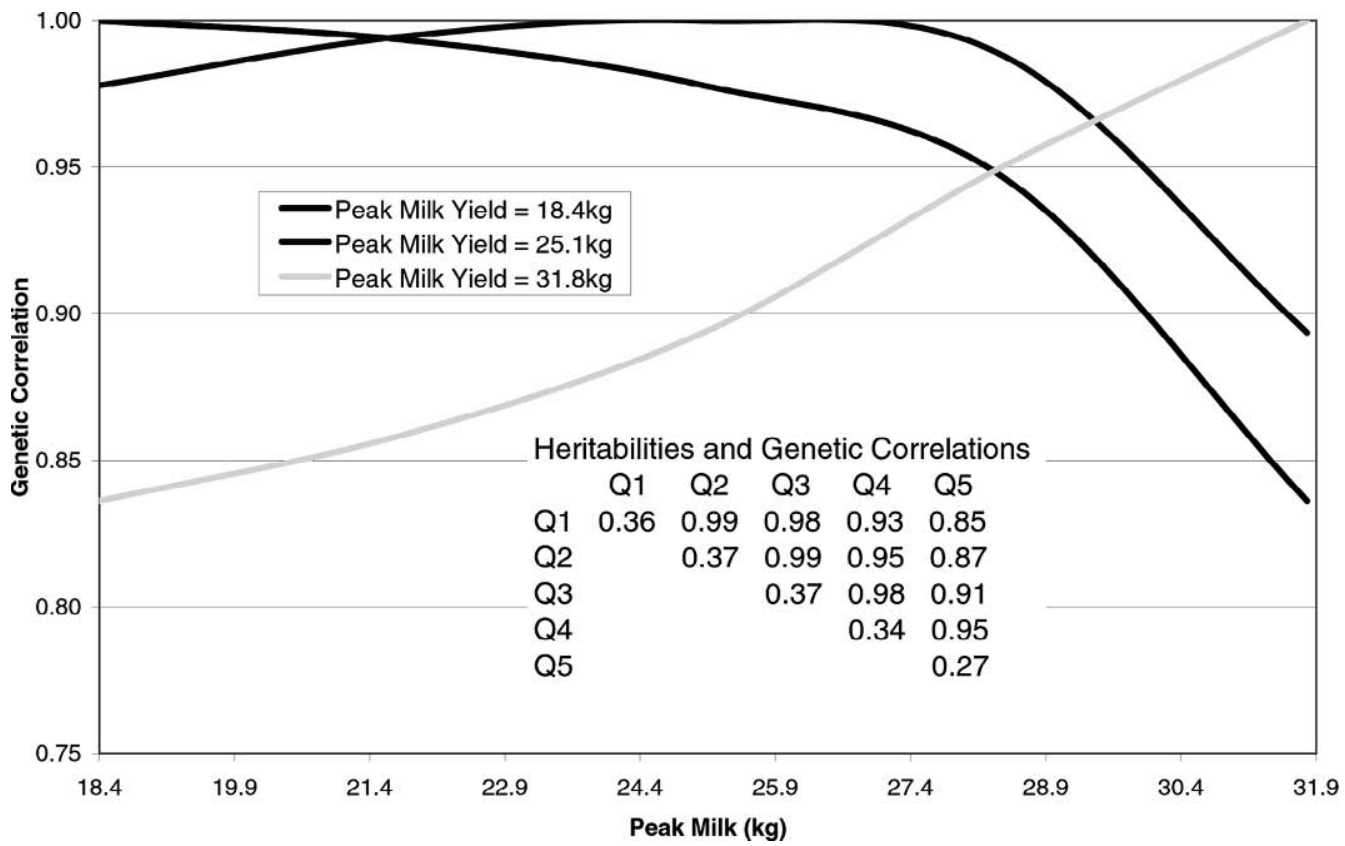

Figure 3. Heritabilities and genetic correlations for herds with varying levels of peak milk yield. 


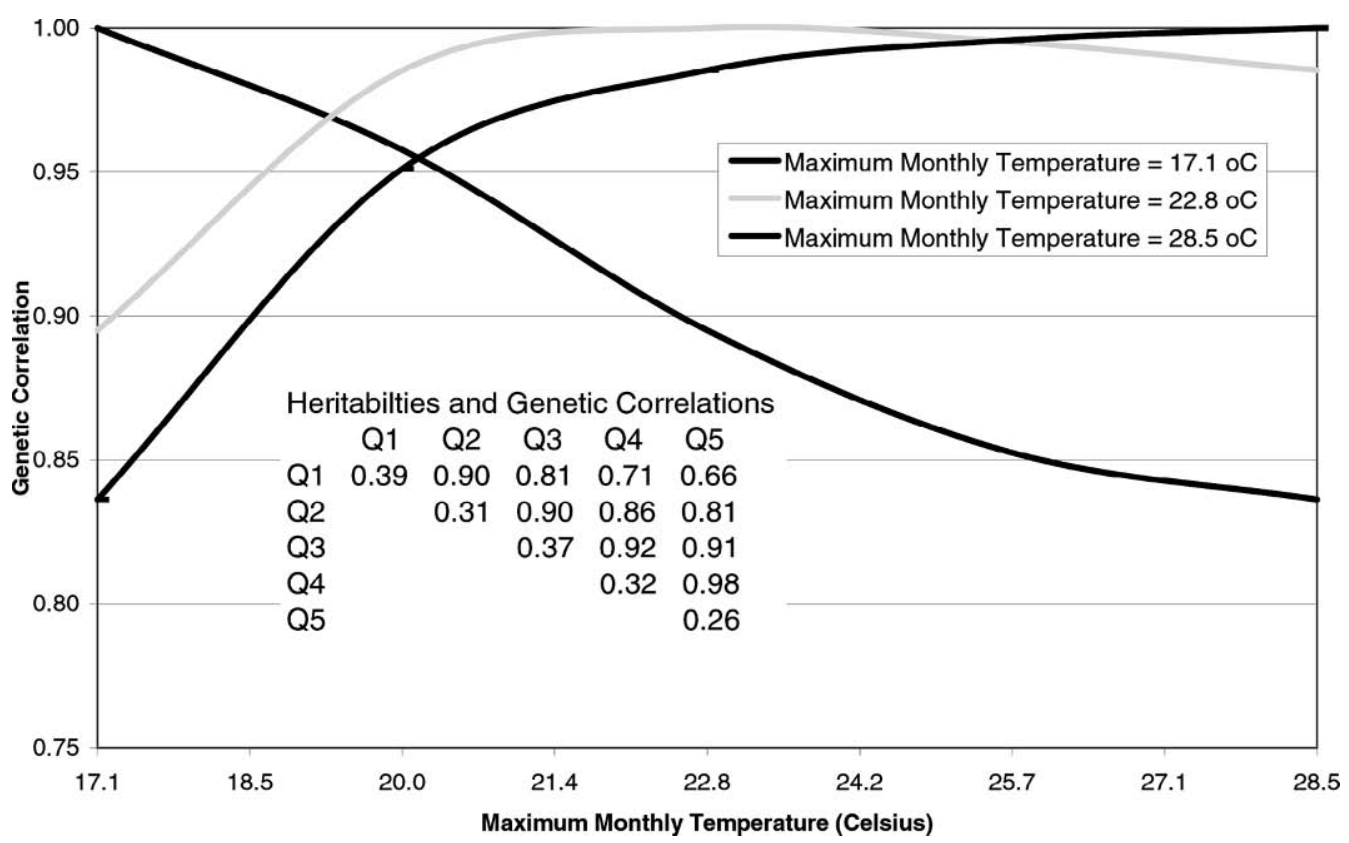

Figure 4. Heritabilities and genetic correlations for herds with varying levels of maximum monthly temperature.

Extremely high heritability, around 0.56, was found in the smallest herds. Estimates decreased as herds got larger, to 0.26 in the largest herds. The smallest herds in this study had a genetic correlation with larger herds of 0.78 , so herd size may be a useful indicator of herd management type. The differences in heritability can be partly attributed to an incomplete heterogeneous variance adjustment, which may have caused genetic variances to be overestimated in extremely small herds.

Herds with lower percentage of North American Holstein genes (Figure 2) had lower heritability than herds that primarily used bulls from the United States and

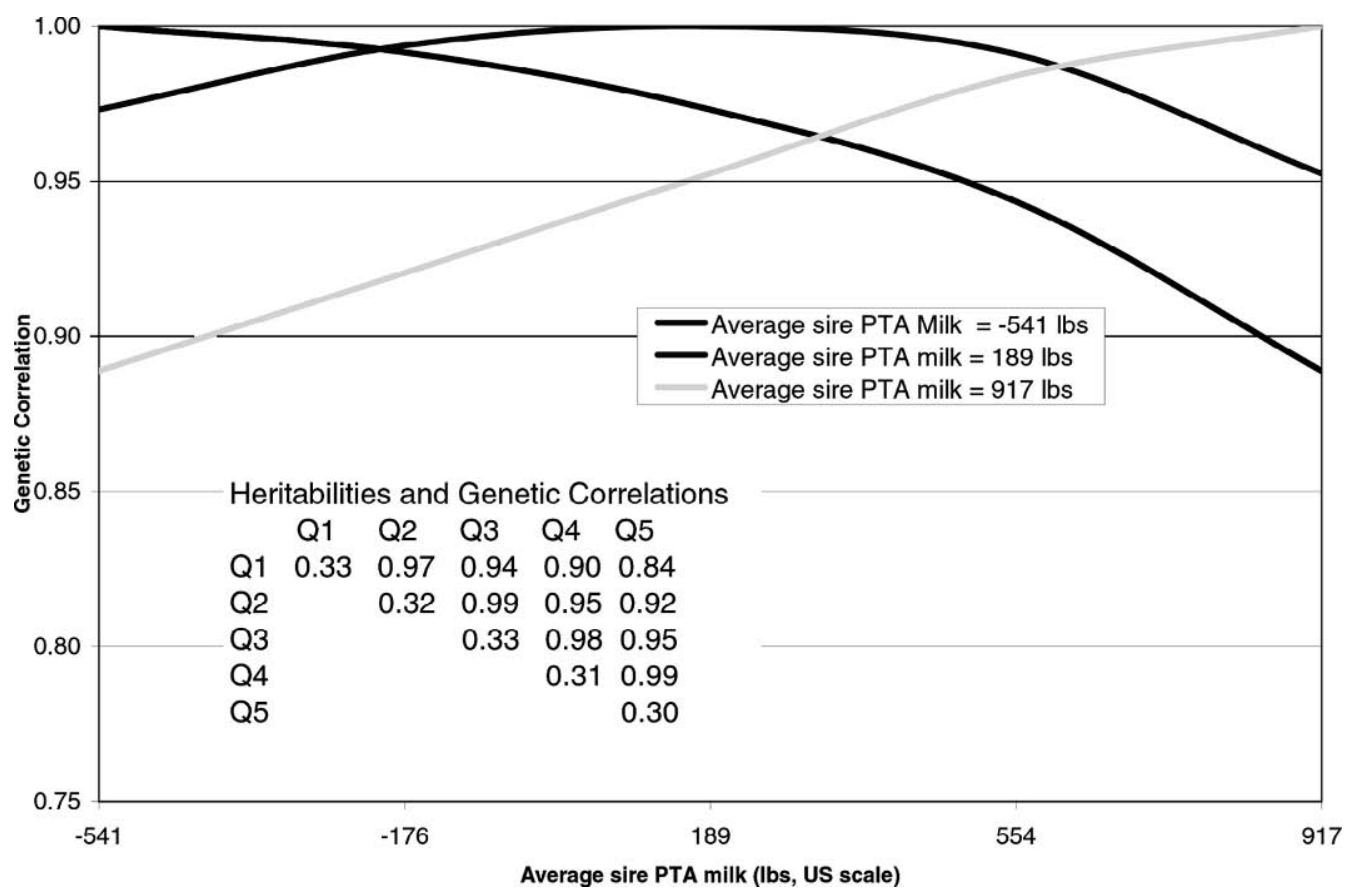

Figure 5. Heritabilities and genetic correlations for herds with varying levels of PTA milk among sires of cows currently in the herd. 


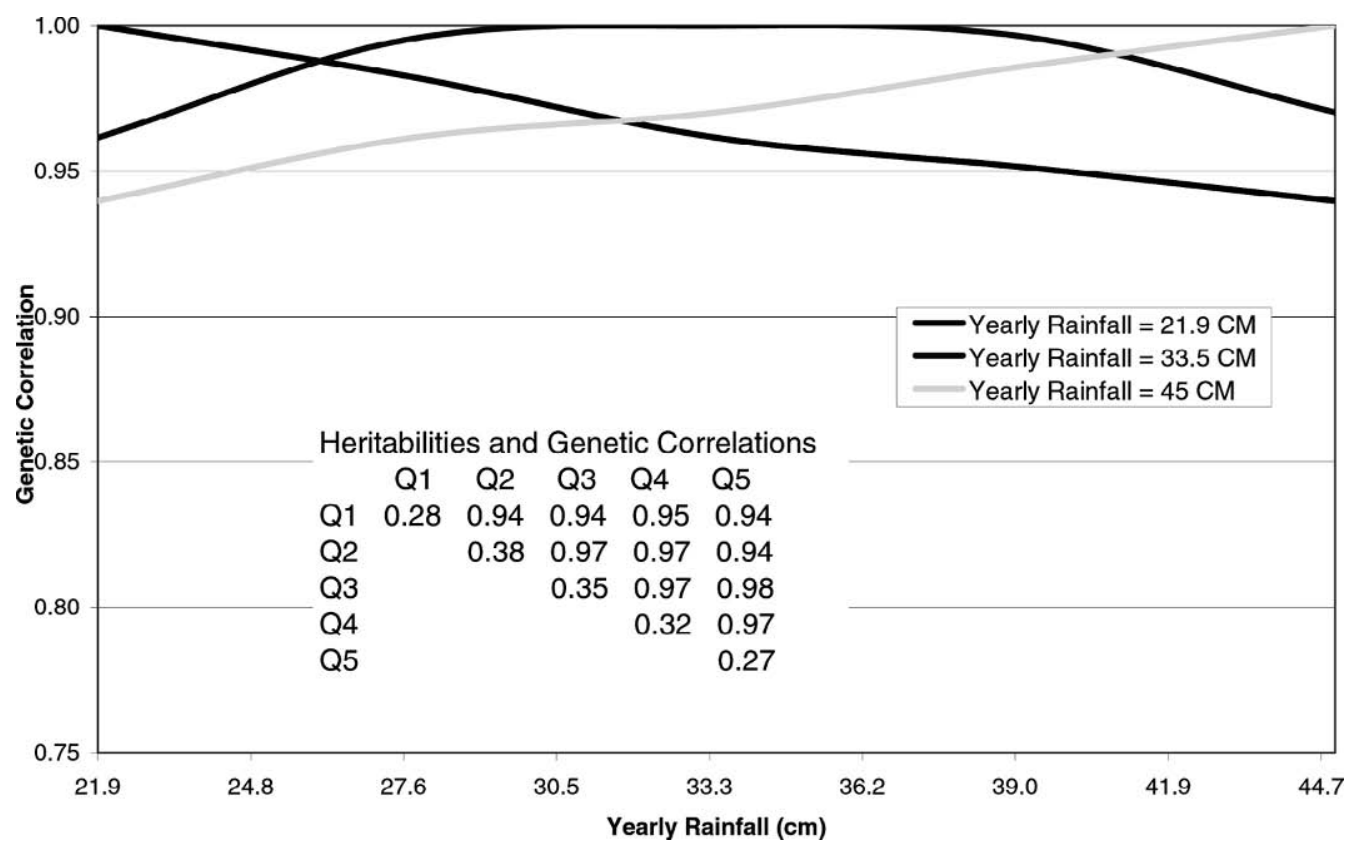

Figure 6. Heritabilities and genetic correlations for herds with varying levels of yearly rainfall.

Canada. The two extreme groups, which averaged $23 \%$ and $97 \%$ of North American Holstein genes respectively, had a genetic correlation of 0.84 . This low correlation could be attributed to missing pedigree information in the lower herds, or it may reflect less genetic potential for milk production within first quintile herds. Heritability was 0.26 in the highest quintile for peak milk yield
(Figure 3), which was lower than in any other quintile groups. This result contradicts previous research, where heritabilities were shown to be higher in high producing herds. The genetic correlation between herds in the top and bottom quintiles was 0.84 .

Temperature (Figure 4) estimates were also not specific to each herd, but significant variation was found

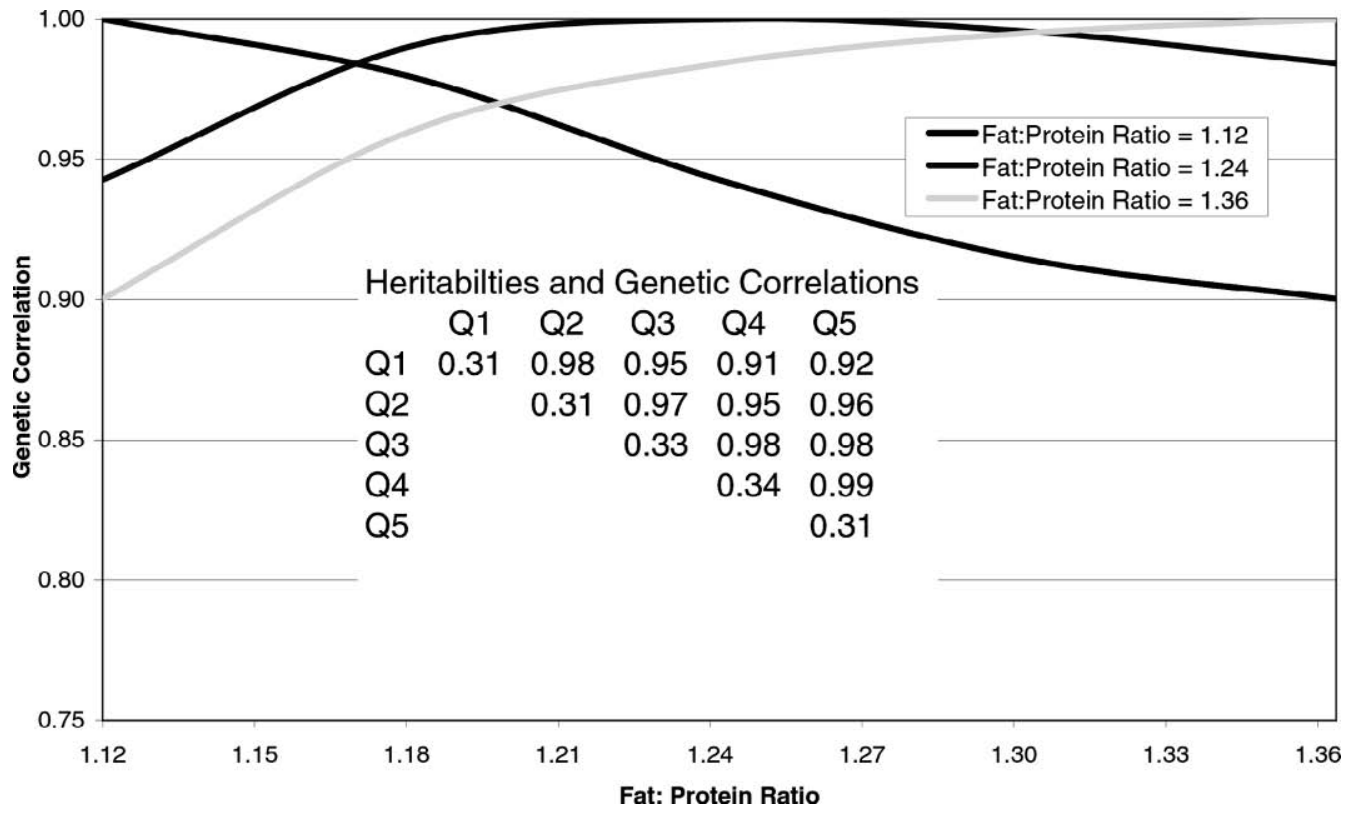

Figure 7. Heritabilities and genetic correlations for herds with varying fat: protein ratios. 


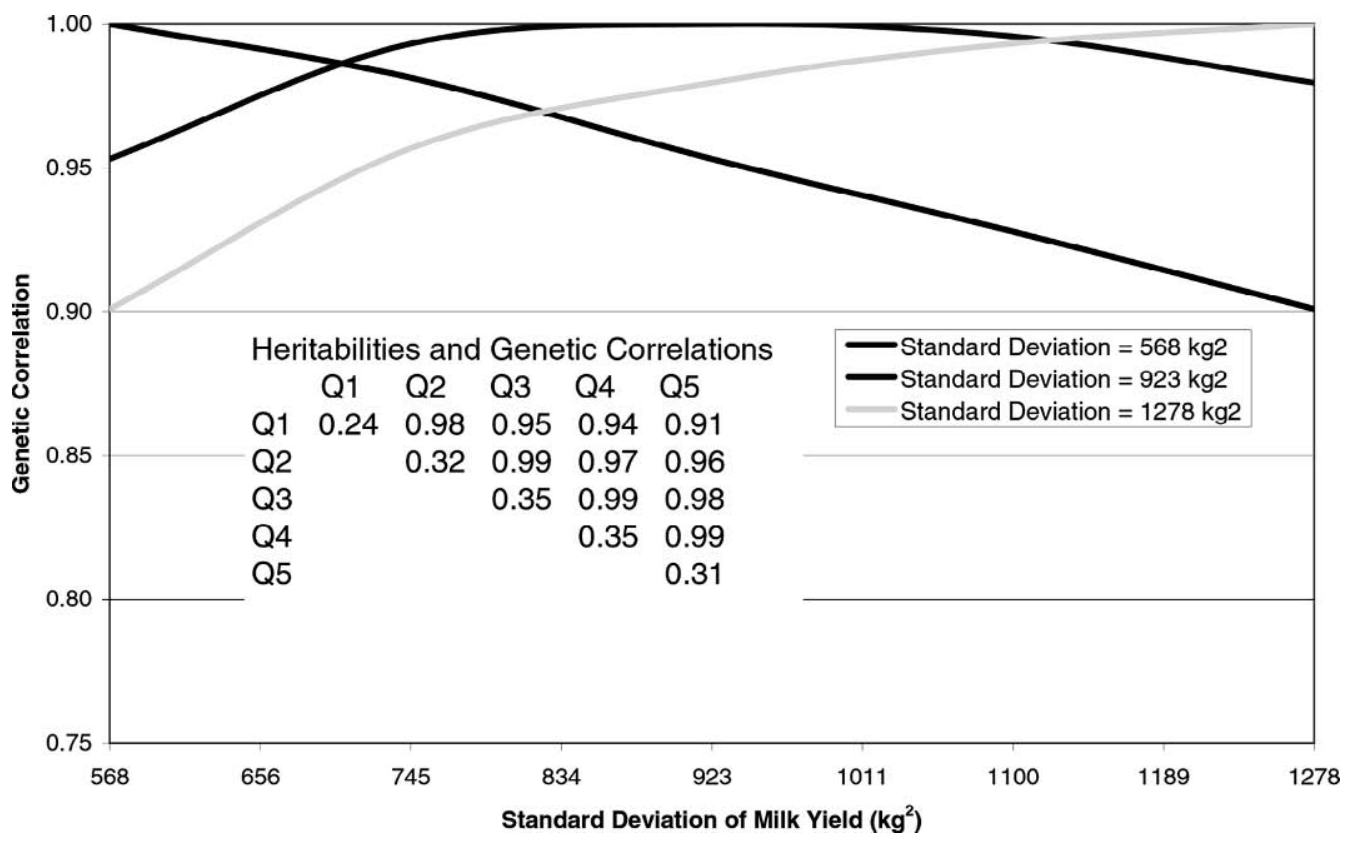

Figure 8. Heritabilities and genetic correlations for herds with varying levels of standard deviation of milk yield.

between herds in warm climates and herds in cool climates. Herds in hot climates had lower heritability $(0.26)$ than herds with cooler climates (0.39). Genetic correlations between herds in extreme environments for temperature were low at 0.84 . This result agrees with that found by Ravagnolo and Misztal (2000) and shows that heat stress may be an important factor in determining specific production environments across countries.

Sire PTA milk, rainfall, fat: protein ratio, and standard deviation of milk yield all had moderate genetic correlations between extreme environments, and therefore their importance in defining unique production environments

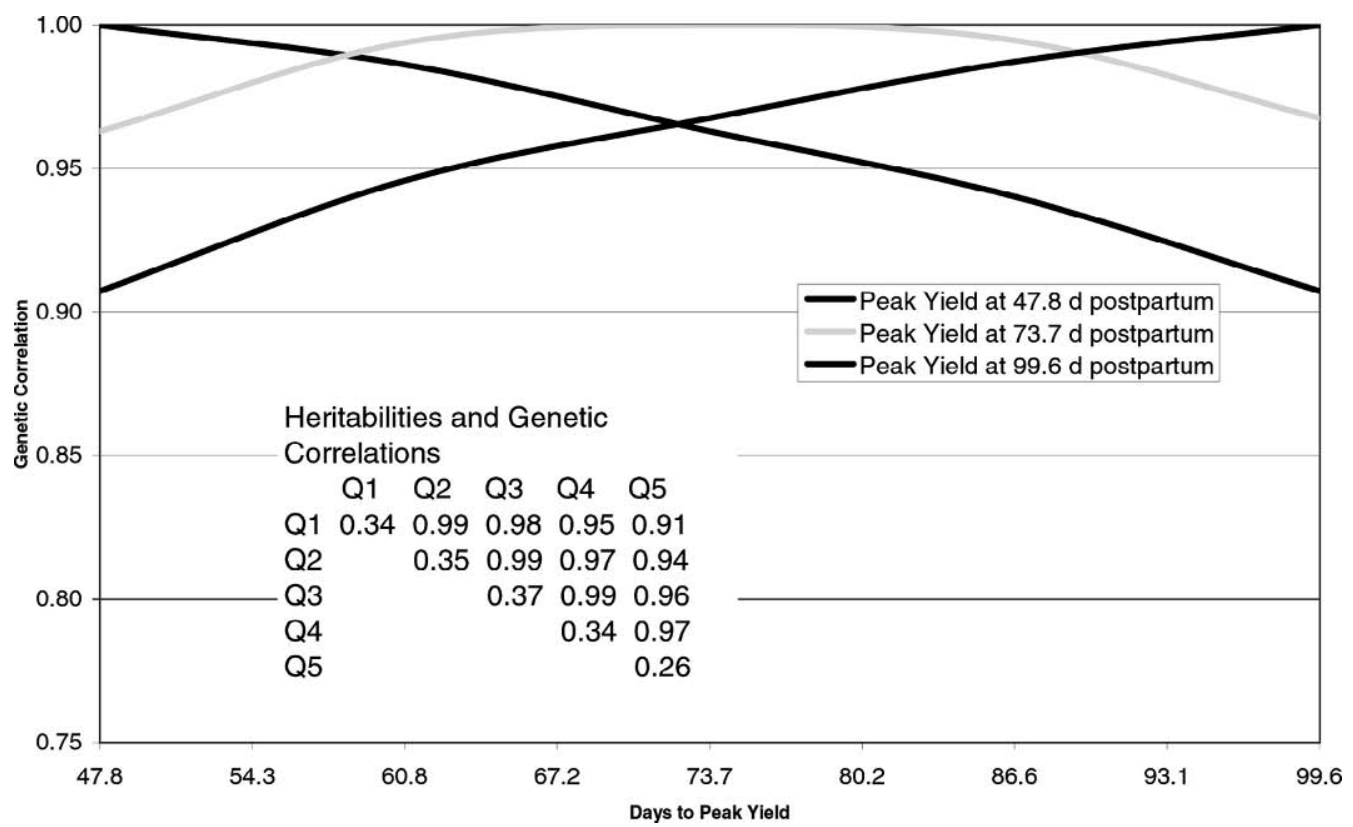

Figure 9. Heritabilities and genetic correlations for herds with varying days to peak yield. 


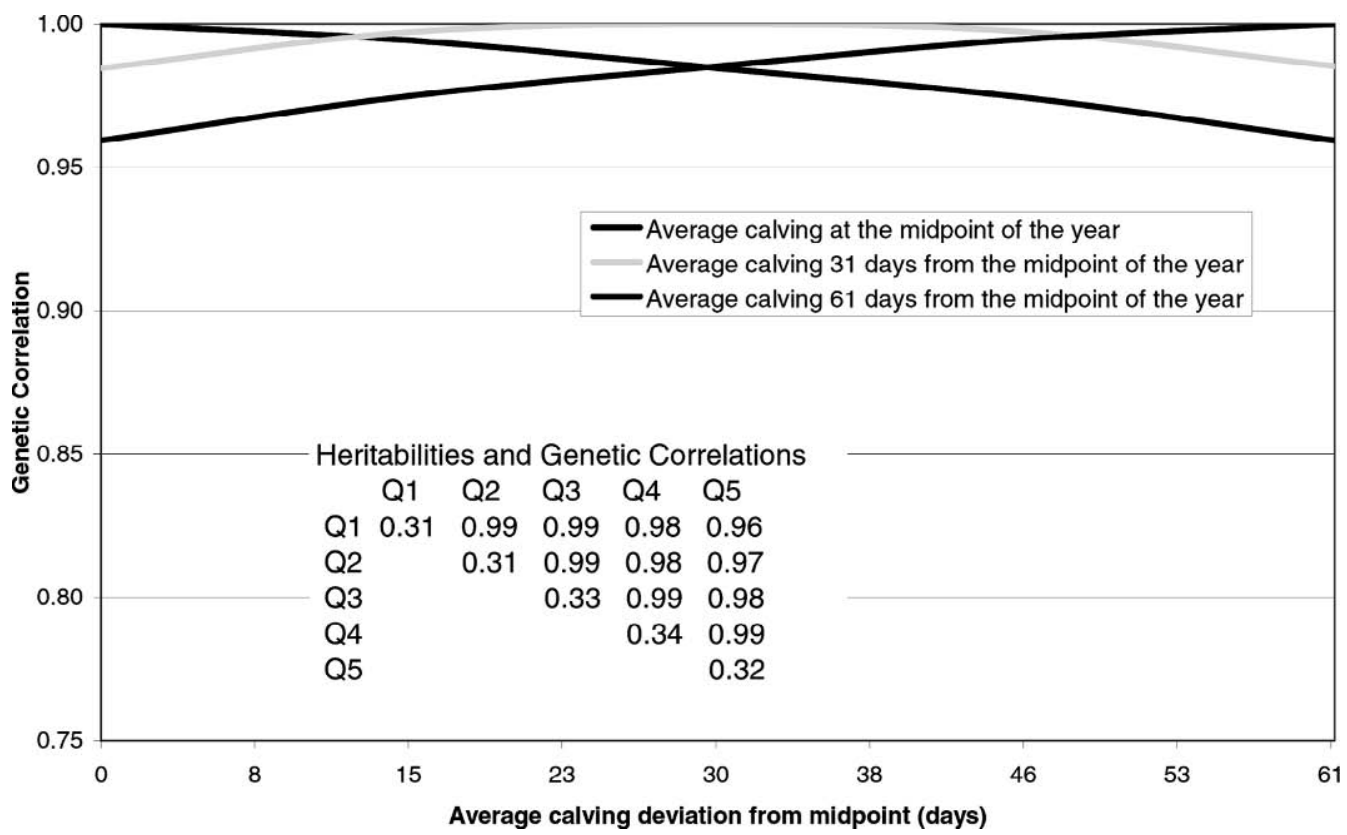

Figure 10. Heritabilities and genetic correlations for herds with different seasonal calving patterns.

could not be determined at first glance. Sire PTA milk (Figure 5), a measure of the genetic level of each herd, was characterized by higher heritability in herds that used lower genetic merit bulls, but correlations with herds that used bulls of higher genetic merit were only 0.84 . When herds were separated into quintiles by annual rainfall (Figure 6), herds with a moderate amount of rainfall had a heritability of 0.35 , and herds with dry or wet climates had heritabilities of 0.28 and 0.27 respectively. The correlation between herds in dry and wet climates was fairly high (0.94), indicating that rainfall might not be a useful variable for defining unique production environments. This may have occurred because rainfall estimates were not specific to each herd,

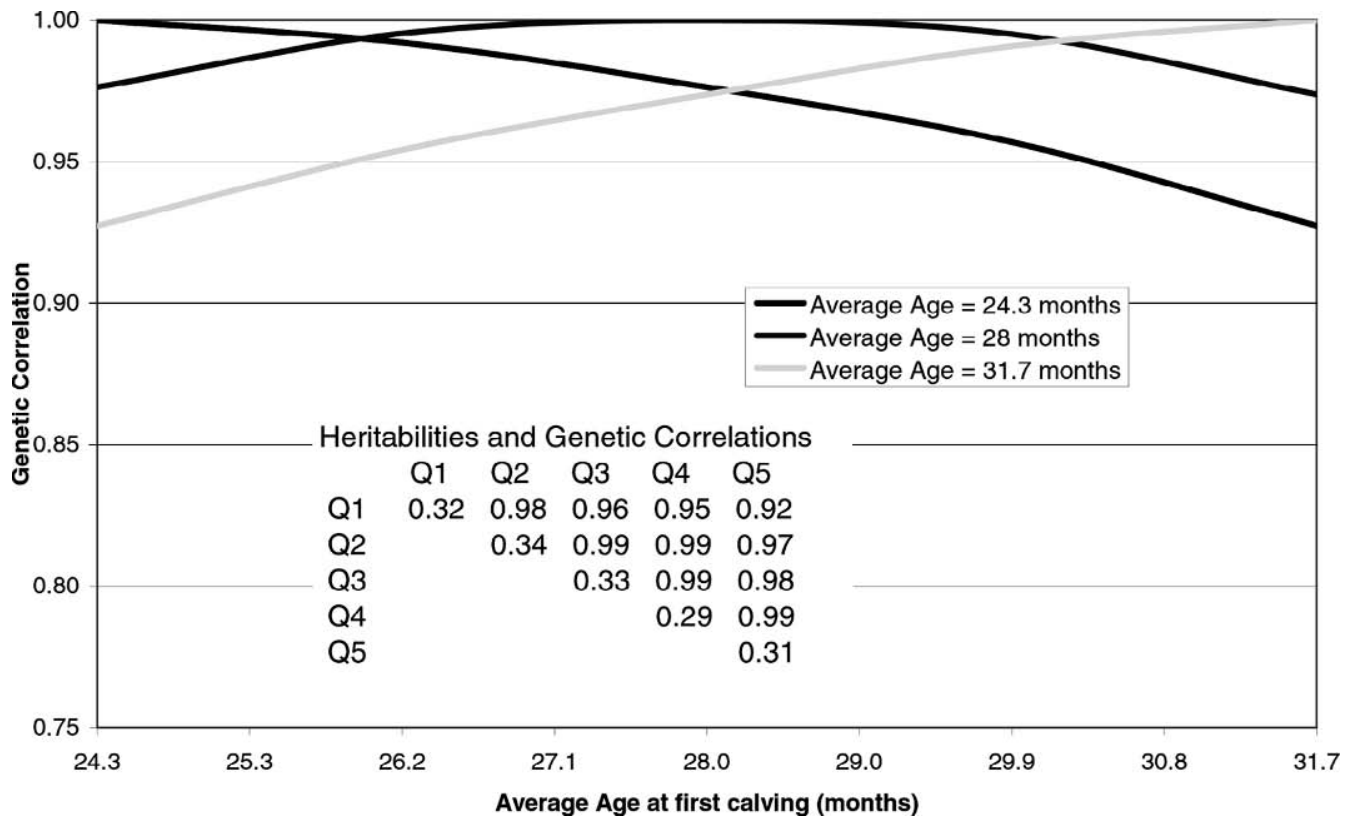

Figure 11. Heritabilities and genetic correlations for herds with varying age at first calving. 


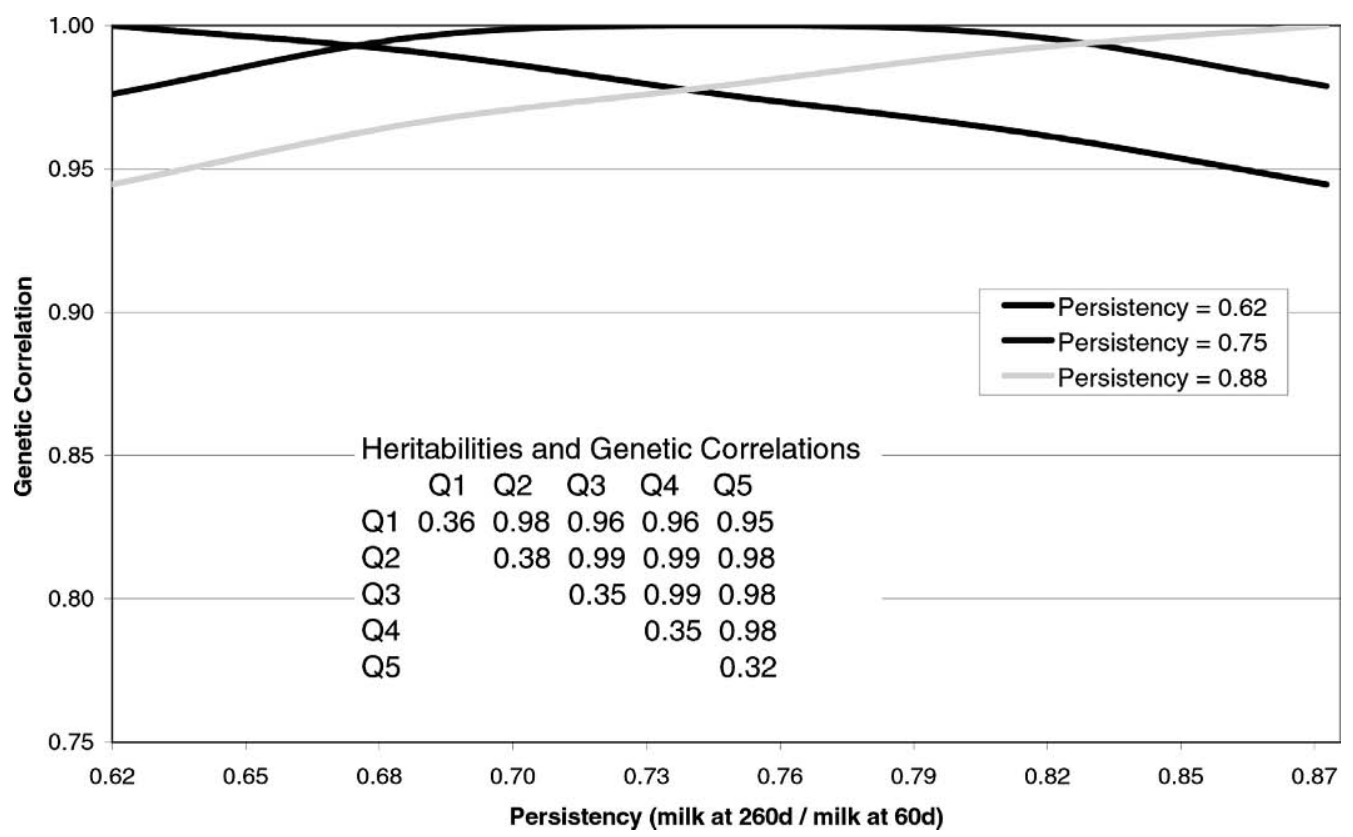

Figure 12. Heritabilities and genetic correlations for herds with varying levels of persistency of milk yield.

but instead specific to a region and a 10 -yr average. Correlations for fat:protein ratio (Figure 7) were approximately 0.90 between herds with a fat:protein ratio of 1.12 and herds with a ratio of 1.36 . This shows that data from herds with a higher fat:protein ratio, generally herds that practice rotational grazing, or some other "extensive" type of management, may be an imprecise predictor of performance in intensively managed herds with a lower fat:protein ratio (Charagu and Peterson, 1998). Standard deviation of milk yield (Figure 8) had a low heritability in the first quintile, but the heritability was much larger in quintiles $2-5$. The first quintile had a relatively low heritability of 0.24 , and the herds with the most variation in milk yield had a heritability of

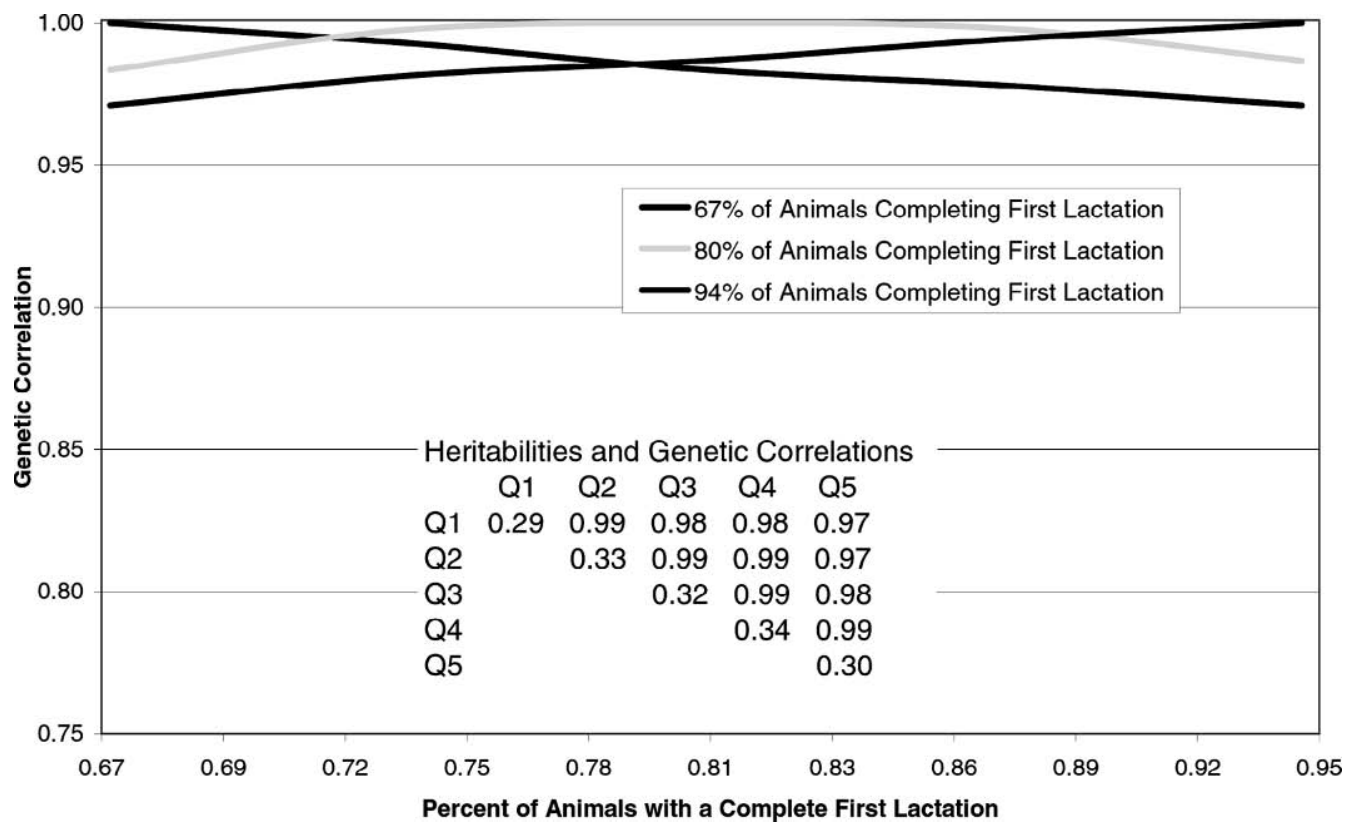

Figure 13. Heritabilities and genetic correlations for herds with varying culling levels. 
0.31 . The genetic correlation between these two groups of herds was 0.91. Days to peak yield (Figure 9) showed a large difference in heritability for herds with peak milk flow occurring around $100 \mathrm{~d}$ postpartum compared with all others. Heritability in herds with a long interval between calving and peak yield was 0.26 , but heritability was at least 0.34 in all other quintiles. The genetic correlation between herds with peak yields occurring at $98 \mathrm{~d}$ and herds with peak milk yield at $48 \mathrm{~d}$ was 0.91 . Average calving date, age at first calving, persistency, and culling percentage showed a very high correlation between herds in extreme environments, which indicates that these variables are not useful for defining unique production environments. Average calving date (Figure 10), calculated as the absolute value of the deviation of calving date from 182, showed a very high correlation (0.96) between herds with seasonal calving and herds with year-round calving practices. Heritability estimates among quintiles were similar. This variable was an indicator of seasonal calving practices in many rotational grazing countries, however these high correlations show that herds with different calving patterns do not necessarily represent different environments. Heritability estimates increased slightly as average age at first calving declined (Figure 11). The correlation between herds with an average age at first calving of 25 and 32 mo was 0.92 . This estimate shows that genotype by environment interaction between herds with late age at first calving and herds with early age at first calving will be relatively small. Persistency of milk yield (Figure 12) was characterized by a correlation of 0.94 between herds with flatter lactation curves and those with less persistent lactations. Correlations less than one could be attributed to differences in feeding and management practices that affect the shape of the lactation curve, or by the prevalence, or lack of, early lactation metabolic disorders. Heritability estimates were slightly higher in herds with less persistency. Genetic correlations between herds that culled $33 \%$ of their animals in the first lactation animals and herds that culled only $6 \%$ of their first lactation animals were 0.97 indicating this variable had almost no importance in determining a unique production environment.

Standard deviation of milk yield, peak milk yield, PTA milk of sires, fat: protein ratio, and percent of North American Holstein genes were all somewhat correlated (Zwald et al., 2001) and these may be double counted if all variables are used when grouping herds into production systems.

\section{CONCLUSIONS}

Important factors affecting genotype by environment interaction were identified based on the correlation between top and bottom quintile groups for each variable.
Variables with genetic correlations deviating the most from unity were: temperature (0.84), herd size (0.79), sire PTA milk (0.89), percent of North American Holstein genes (0.83), peak milk yield (0.84), fat:protein ratio (0.90), and standard deviation of milk yield (0.90). Future research will focus on grouping herds into unique production environments based on these variables, but correlations between variables must be considered. The results shown in this paper suggest that bulls' daughters may perform differently in large herds versus small herds, or in herds with a hot climate versus herds with a cool climate. Present genetic evaluation systems do not consider genotype by environment interactions within countries. If herds were grouped according to these variables rather than by country borders, genetic evaluations could be computed for each unique production system. This could ultimately increase genetic progress by increasing the accuracy of international genetic evaluations for each management situation.

\section{REFERENCES}

Banos, G., and A. Sigurdsson. 1996. Contemporary methods for the Use of International data in National Genetic Evaluations. J. Dairy Sci. 79:1117-1125.

Banos, G., and C. Smith. 1991. Selection within and across populations in livestock improvement. J. Anim. Sci. 69:2387-2394.

Charagu, P., and R. Peterson. 1998. Estimation of GXE effects for economic efficiency among daughters of Canadian and New Zealand sires in Canadian and New Zealand dairy herds. Proceedings of the 1998 Interbull meeting, Roturua, New Zealand, Bulletin no. 17:105-109.

Cromie, A. R., D. L. Kelleher, F. J. Gordon, and M. Rath. 1998. Genotype by environment interaction for milk production traits in Holstein Friesian dairy cattle in Ireland. Proc. 1998 Interbull meeting., Rotorua, New Zealand XVII:100-104.

Hoare, R. 1996. WorldClimate. Buttle and Tuttle Ltd, http://www.worldclimate.com. Accessed June 10, 2000.

Kirkpatrick, M., D. Lofsvold, and M. Bulmer. 1990. Analysis of the inheritance, selection and evolution of growth trajectories. Genetics 124:979-993.

Lohuis, M. M., and J. C. M. Dekkers. 1998. Merits of borderless evaluations. Proc. 6th World Congr. Genet. Appl. Livest. Prod., Armidale, Australia XXVI:169-172.

Pool, M. H., and T. H. E. Meuwissen. 2000. Reduction of the number of parameters needed for a polynomial random regression test day model. Livest. Prod. Sci. 64:133.

Ravagnolo, O., and I. Misztal. 2000. Genetic component of heat stress in dairy cattle, parameter estimation. J. Dairy Sci. 83:2126.

Rekaya, R., M. J. Carabano, and M. A. Toro. 2000. Bayesian Analysis of Lactation Curves of Holstein-Friesian Cattle Using a Nonlinear Model. J. Dairy Sci. 83:2691.

Schaeffer, L. R. 1994. Multiple-country comparison of dairy sires. J. Dairy Sci. 77:2671-2678.

Weigel, K. A., and R. Rekaya. 2000. A multiple-trait herd cluster model for international dairy sire evaluation. J. Dairy Sci. 83:815-821.

Weigel, K. A., and N. R. Zwald. 2002. Selection and Grouping of Herds in International Genetic Evaluation of Daughter Performance Records. Proc. 2002 Interbull meeting, Interlaaken, Switzerland.

Wiggans, G. R., and P. M. VanRaden. 1991. Method and effect of adjustment for heterogeneous variance. J. Dairy Sci. 74:4350-4357.

Zwald, N. R., K. A. Weigel, R. Rekaya, and W. F. Fikse. 2001. Characterization of dairy production systems in countries that participate in the international bull evaluation service. J. Dairy Sci. $84: 2530-2534$. 